\title{
Effect of Captopril and Melatonin on Fibrotic Rebuilding of the Aorta in 24 Hour Light-Induced Hypertension
}

\author{
K. REPOVÁ-BEDNÁROVÁ ${ }^{1}$, S. AZIRIOVÁ ${ }^{1}$, J. HRENÁK ${ }^{1}$, K. KRAJČÍROVIČOVÁ ${ }^{1}$, \\ M. ADAMCOVÁ ${ }^{4}$, L. PAULIS ${ }^{1}$, F. ŠIMKO ${ }^{1,2,3,5}$
}

${ }^{1}$ Department of Pathophysiology and ${ }^{2}$ Third Clinic of Medicine, School of Medicine, Comenius University, Bratislava, Slovak Republic, ${ }^{3}$ Institute of Experimental Endocrinology, Slovak Academy of Sciences, Bratislava, Slovak Republic, ${ }^{4}$ Department of Physiology, Faculty of Medicine in Hradec Kralove, Charles University in Prague, Hradec Kralove, Czech Republic, ${ }^{5}$ Centrum of Excellence NOREG, Slovak Republic

Received March 15, 2013

Accepted June 18, 2013

\section{Summary}

Chronic continuous light exposure leads to melatonin deficiency along with complex neurohumoral activation resulting in hypertension development in rats. The aim of this study was to show, whether continuous light induces fibrotic rebuilding of the aorta and whether the treatment with melatonin or angiotensin converting enzyme inhibitor captopril can prevent these potential alterations. In a six-week experiment, 3-month-old Wistar rats were divided into 4 groups (ten per group): controls, rats exposed to continuous light, exposed to continuous light plus treated with captopril $(100 \mathrm{mg} / \mathrm{kg} / 24 \mathrm{~h})$ and exposed to continuous light plus treated with melatonin $(10 \mathrm{mg} / \mathrm{kg} / 24 \mathrm{~h})$. Systolic blood pressure (SBP) and collagen type I and III in the media of thoracic aorta were measured. Continuous light induced hypertension and fibrotic rebuilding of the aorta in terms of enhancement of collagen I and III concentration in the aortic media. Both captopril and melatonin prevented SBP rise and reduced collagen III concentration in the aorta. However, only melatonin reduced collagen I and the sum of collagen I and III in the aortic tissue. We conclude that in continuous light-induced hypertension, administration of melatonin, along with SBP reduction, decreases collagen I and III concentration in the aorta. It is suggested that antifibrotic effect of melatonin may reduce the stiffness of the aorta and small arteries and beneficially influence the nature of the pulse wave and peripheral vascular resistance.

\section{Key words}

Continuous light • Hypertension • Fibrosis • Melatonin • Captopril

- Collagen I and III

\section{Corresponding author}

Fedor Simko, Department of Pathophysiology, School of Medicine, Comenius University, Sasinkova 4, 81372 Bratislava, Slovak Republic. Fax: +421-(0)2-59357601.

E-mail: fedor.simko@fmed.uniba.sk

\section{Introduction}

Fibrotic rebuilding of the heart, aorta, small arteries or kidneys in the condition of chronically increased blood pressure represents the principal tissue damage resulting in deterioration of organ function and worsening of prognosis. It is generally assumed that attenuation of the pathological remodeling of the heart and large vessels diminishes cardiovascular risk. This stimulates the search for new approaches and drugs against the consequences of hemodynamic overloadinduced cardiovascular remodeling in variable models of experimental hypertension and in clinical conditions (Paulis et al. 2009, 2010b, Pechanova et al. 2007, Rezzani et al. 2010, Schiffrin 2012, Simko et al. 2004, 2009, 2010).

Melatonin was proven to express antihypertensive action in several animal models of hypertension (Li et al. 2009, Paulis et al. 2010a, Paulis and Simko 2007, Simko et al. 2009, Simko and Paulis 2007, Simko et al. 2010, Xia et al. 2008) and in normotensive and hypertensive humans (Grossman et al. 2006, 2011, Paulis et al. 2012, Rechcinski et al. 2010, Scheer et al. 2004, Simko and Pechanova 2009) and the 
deficit of melatonin results in blood pressure rise (Jonas et al. 2003, Simko et al. 2013, Zeman et al. 2005). The model of continuous illumination-induced hypertension represents a melatonin-deficient blood pressure elevation as a result of reduced nocturnal melatonin secretion and complex neurohumoral activation (Simko et al. 2010, 2013). Previously it has been shown in our laboratory that continuous light-induced increase in blood pressure was associated with left ventricular hypertrophy and fibrosis and the administration of melatonin prevented oxidative stress and fibrosis of the left ventricle (Simko et al. 2010).

Melatonin exerts manifold protection on cardiovascular system. This indolamine has a remarkable antioxidant and scavenging effect both at extra- and intracellular level (Reiter et al. 2007, Tengattini et al. 2008). Furthermore, melatonin has also antihypertensive, antiproliferative and sympatholytic effects (Simko and Paulis 2007, 2012, 2013). Similarly, angiotensin converting enzyme (ACE) inhibitors, including captopril, decrease blood pressure, remodeling of the heart and vessels, and neurohumoral activation, resulting in cardiovascular protection (Simko et al. 2003).

In this experiment we investigated, whether light-induced hypertension induces (or not) fibrosis of the aorta and whether this potential excess of collagen can be modified by melatonin or angiotensin converting enzyme inhibitor captopril.

\section{Methods}

\section{Animals and treatment}

3-month-old male Wistar rats were randomly divided into four groups $(\mathrm{n}=10$ each): controls (c), rats exposed to continuous light (24), exposed to continuous light plus treated with captopril (100 mg/kg/24 h) (24C) (Egis Pharmaceuticals Ltd., Budapest, Hungary) and exposed to continuous light plus treated with melatonin $(10 \mathrm{mg} / \mathrm{kg} / 24 \mathrm{~h}) \quad(24 \mathrm{M}) \quad$ (Sigma Chemical Co., Deisenhofen, Germany). All treatment drugs were administrated perorally dissolved in drinking water each day during the six weeks of experiment. The concentration of these drugs was adjusted to daily water consumptions to ensure the correct dosage. Melatonin containing solutions were protected from light. All rats were housed at a temperature of $22-24{ }^{\circ} \mathrm{C}$ in individual cages and were freely fed a regular pellet diet in accordance with the Guide for the Care and Use of Laboratory Animals published by the US National
Institutes of Health (NIH publication no. 8523, revised 1985).

Systolic blood pressure (SBP) was measured each week by noninvasive tail-cuff plethysmography (Hugo-Sachs Elektronik, Freiburg, Germany). After six weeks of experiment the animals were sacrificed by decapitation and the samples of thoracic aorta (approximately $50 \mathrm{mg}$ ) were used for the analysis of collagen type I and III in the media.

\section{Collagen type I and III in aortic media}

Samples from the thoracic aorta were fixed in $4 \%$ formaldehyde (Sigma Chemie, Germany) for $24 \mathrm{~h}$, embedded in paraffin, cut in $5 \mu \mathrm{m}$ slices. Deparaffinized and rehydrated $5 \mu \mathrm{m}$ thick slices were stained with picrosirius red as follows: the slides were submerged in $0.2 \%$ phosphomolybden acid for clearing the cytoplasm, then the slides were stained with $0.1 \%$ sirius red F3BA in a saturated water solution of picric acid for $90 \mathrm{~min}$. The slides were washed $2 \mathrm{~min}$ in $0.01 \mathrm{~N} \mathrm{HCl}$, dehydrated and mounted.

10 randomly selected places of aorta on each slide were viewed by microscopy under polarized light and documented with a digital photographic camera PowerShot S5 IS (Canon, Japan). The size of each taken picture of aorta was $4.2 \times 3.1 \mathrm{~mm}$. Then, the parts of aortic media sized $0.58 \times 0.58 \mathrm{~mm}(1 \mathrm{px}=0.39 \mu \mathrm{m})$ from each picture were selected and evaluated by histomorphometry using the ImageJ software v.1.43u (National Institutes of Health, Bethesda, USA). Threshold values were determined for the particular colors of spectrum, red to yellow for thick collagen I and green for thin collagen III, the numbers of pixels of each color were counted and the percentage of the picture's area was calculated.

\section{Statistical analysis}

For statistical analysis the software GraphPad InStat version 3.06 (GraphPad Software Inc, San Diego, CA, USA) was used. The results were expressed as mean \pm standard error of mean (SEM). One-way, two-tailed analysis of variance (ANOVA) and the Bonferroni posttest were used. Differences were considered significant if the $\mathrm{P}$ value was less than 0.05 .

\section{Results}

During the six weeks of treatment, the average SBP in controls and in 24-group were 
$126.06 \pm 0.25 \mathrm{mmHg}$ and $143.03 \pm 1.86 \mathrm{mmHg}$, respectively (increased by $13 \%, \mathrm{P}<0.05$ ). Systolic blood pressure decreased significantly $(\mathrm{P}<0.05)$ after both captopril $(14 \%)$ and melatonin (9\%) treatment (Fig. 1).

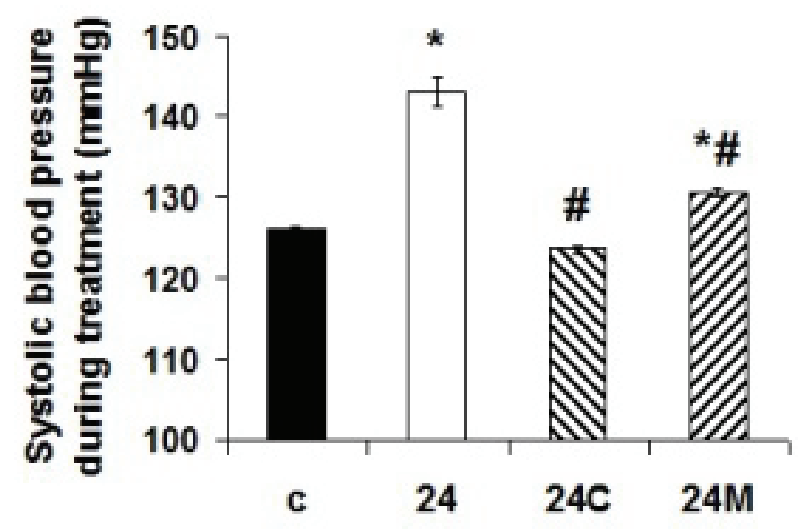

Fig. 1. The effect of captopril (24C) and melatonin (24M) on average systolic blood pressure during 6 weeks of experiment in $24 \mathrm{~h}$ continuous light-induced hypertension (24). c, Wistar controls. ${ }^{*} \mathrm{P}<0.05$ vs. c; \# $\mathrm{P}<0.05$ vs. 24

The level of collagen I in aortic media was $7.77 \pm 0.73 \%$ and $29.04 \pm 1.77 \%$ in controls and 24-group, respectively (increased by $274 \%, \mathrm{P}<0.05$ ). Only melatonin significantly reduced collagen I (by $39 \%, \mathrm{P}<0.05$ ) (Fig. 2A, 3). The level of collagen III in aortic media was $0.0012 \pm 0.0003 \%$ and $0.0319 \pm 0.0069 \%$ in controls and in 24-group, respectively $(\mathrm{P}<0.05)$. Both captopril ( $47 \%)$ and melatonin $(88 \%)$ decreased collagen III level $(\mathrm{P}<0.05)$ (Fig. 2B, 3). The sum of collagen I and III in aortic media was $7.77 \pm 0.73 \%$ and $29.35 \pm 1.95 \%$ in controls and in 24 -group, respectively (increased by $277 \%, \mathrm{P}<0.05$ ). Only melatonin reduced the sum of collagen I and III by $39 \%$ $(\mathrm{P}<0.05)$ (Fig. 2C, 3).

\section{Discussion}

Continuous application of $24 \mathrm{~h}$ /day light during six weeks resulted in hypertension development and fibrotic rebuilding of the aorta in terms of enhancement of collagen I and III concentration in the media. Both captopril and melatonin prevented blood pressure rise and reduced collagen III concentration in the aorta. However, only melatonin reduced collagen $\mathrm{I}$ and the sum of collagen I and III in the aortic tissue.

There are two experimental approaches that severely compromise melatonin production and disturb its regulatory role in daily rhythmicity, i.e. pinealectomy and continuous light exposure (Simko and Paulis 2013).

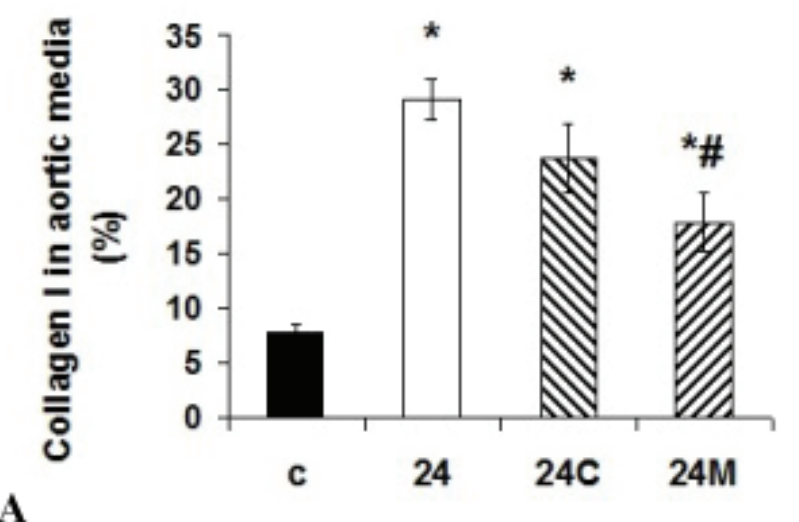

$\mathbf{A}$
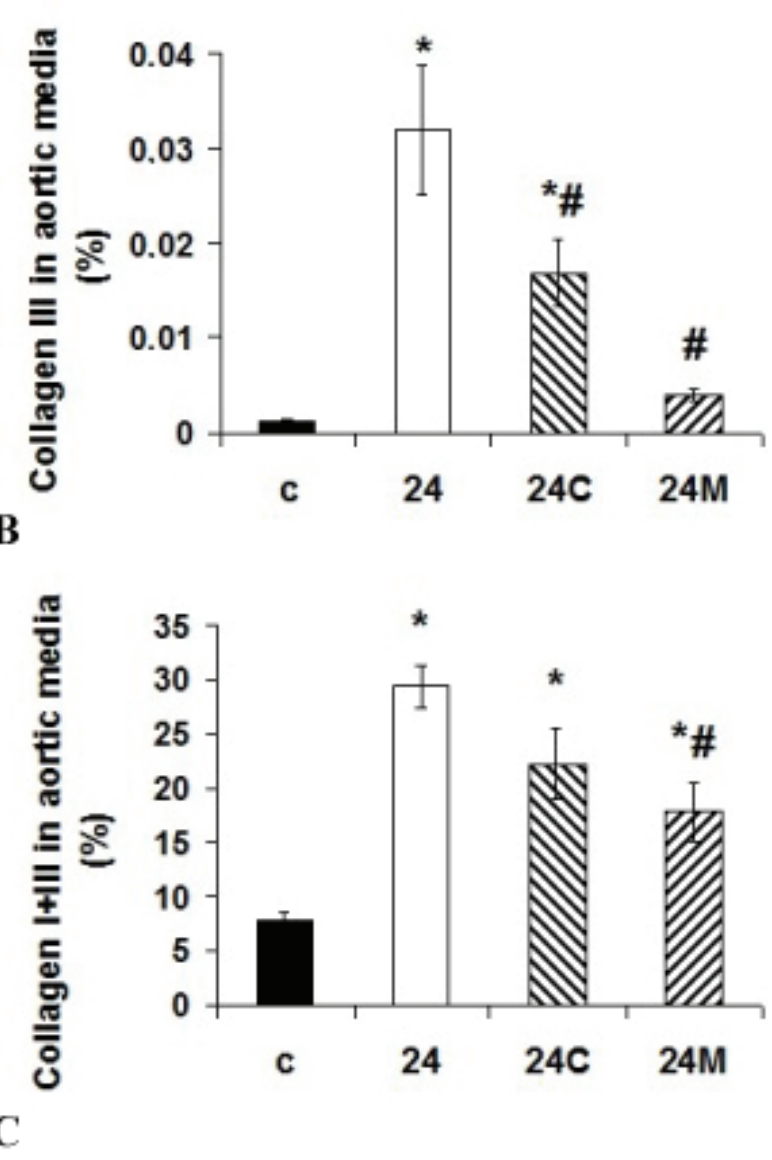

Fig. 2. The effect of captopril (24C) and melatonin (24M) on the concentration of collagen I (A), III (B) and the sum of collagen I and III (C) in the aortic media in $24 \mathrm{~h}$ continuous light-induced hypertension (24). C, Wistar controls. * $\mathrm{P}<0.05$ vs. c; \# $\mathrm{P}<0.05$ vs. 24

However, in the light-induced "melatonin-deficient" hypertension development, several neurohumoral mechanisms seem to participate, including increased epinephrine synthesis in the adrenal gland (IvanisevicMilovanovic et al. 1995), the shortage of sympatholytic effect of melatonin (Arangino et al. 1999), increased expression of angiotensin II level in the left ventricle (Simko et al. 2010), or activation of adrenocorticotropic 

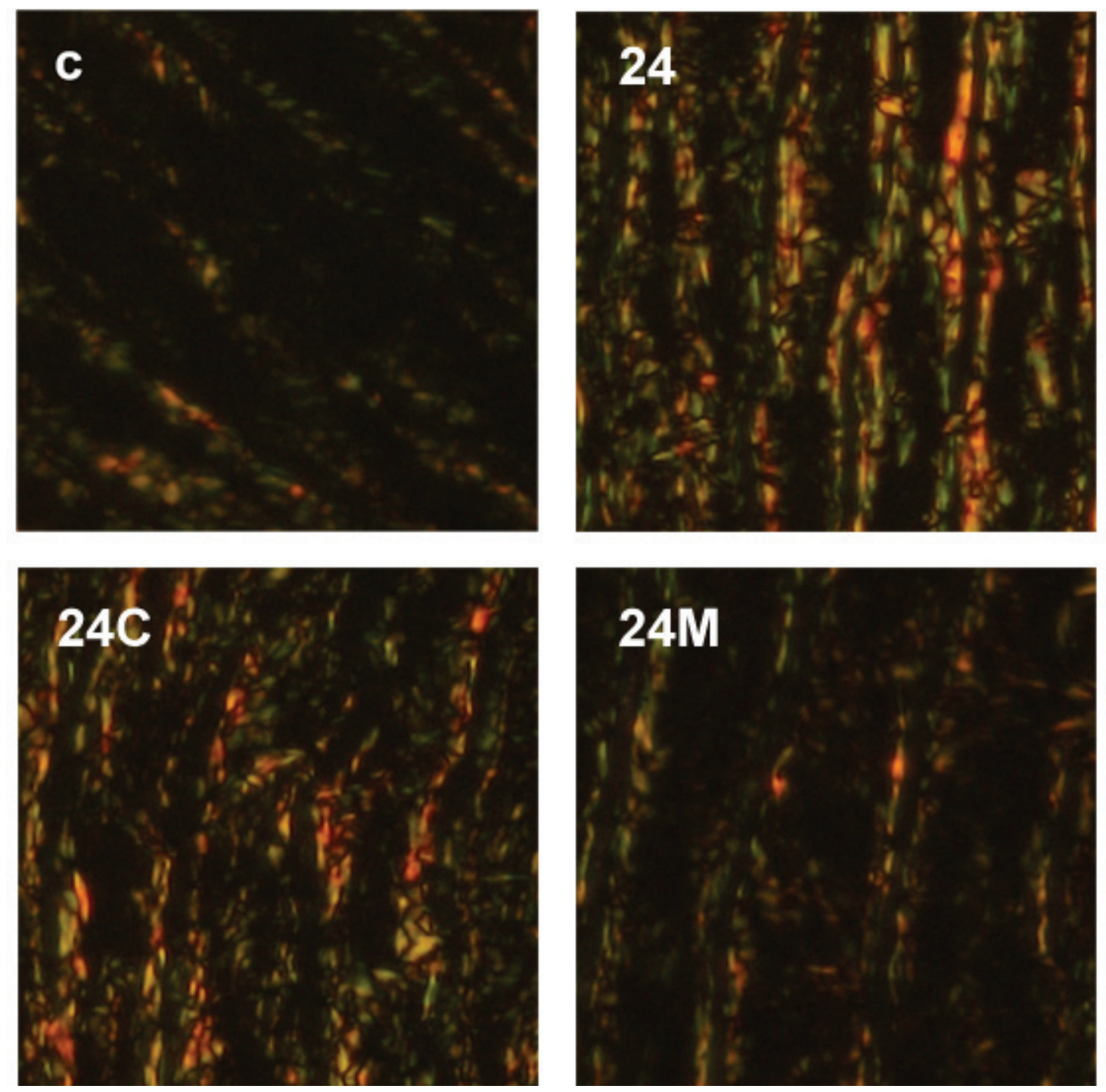

Fig. 3. The effect of captopril (24C) and melatonin (24M) on the concentration of collagen in the aortic media in $24 \mathrm{~h}$ continuous lightinduced hypertension (24). Specimens are stained with picrosirius red and evaluated in polarized light: red to yellow color represents collagen I and green color represents collagen III. c, Wistar controls

hormone - glucocorticoid axis (Milosevic et al. 2005). It is suggested that melatonin deficiency in continuous light exposed animals triggers a sequence of neurohumoral imbalances, which may contribute to blood pressure alterations and target organ damage via variable indirect (vasoconstrictive and circulating fluid enhancing) or direct mechanisms (Simko and Paulis 2013).

In our previous experiments it has been shown that light-induced hypertension stimulated hypertrophy and fibrosis development in the left ventricle (Simko et al. 2010). Both captopril and melatonin prevented blood pressure increase. However, only melatonin decreased the concentration of insoluble and the total collagen in the left ventricle, although only captopril reduced left ventricular hypertrophy development (Simko et al. 2010).
Similarly, melatonin reduced left ventricular fibrosis in L-NAME-induced hypertension (Paulis et al. 2009) and in spontaneously hypertensive rats (Simko et al. 2009).

It has been shown that melatonin improves endothelial function in terms of enhancement of nitric oxide synthesis and reduction of its degradation (Dominguez-Rodriguez et al. 2010, Paulis et al. 2010a, Rezzani et al. 2010, Tengattini et al. 2008) and attenuates the remodeling of smaller arteries (Paulis et al. 2010b). However, according to our knowledge, the data referring to the protective effect of melatonin in the aorta and large conduit arteries are missing. In this experiment melatonin prominently reduced the collagen I and III concentrations. Within the cardiovascular tissues at least twelve types of collagen were disclosed, however, 
collagen I and III seems to play the dominant role (Pelouch et al. 1995, Simko and Paulis 2012). Collagen I fibers have an extremely high tensile strength (Pelouch et al. 1995, Weber 1989) and in a decisive manner determine the stiffness of the myocardium or aorta. Type III collagen is more distensible than collagen I and seems to maintain the structural integrity of the network (Weber 1989). These collagen types together are responsible for tensile strength, but also contribute, together with elastin, somewhat to the extensile properties of the aorta (Dobrin and Mrkvicka 1994). Collagen linking to vascular smooth muscle cells significantly contributes to the stiffness of the aorta and conduit arteries (Schiffrin 2012), and enhancement of the aortic stiffness seems to be prognostically unfavorable (Schiffrin 2012). Several antihypertensive agents, including those interfering with angiotensin II production or effect, aldosterone receptor blockers or calcium channel blockers, were shown to reduce vascular stiffness, potentially through their inhibition of the production of growth factors resulting in the attenuation of proliferation and fibrosis (Schiffrin 2012).

The potent antifibrotic effect of melatonin in the aorta shown in our experiment, which was more prominent than that of captopril, may hardly be determined purely by melatonin's hemodynamic effect, since the SBP reduction, although significant, is relatively week compared to captopril. More plausible explanation resides in the prominent antioxidative effect of melatonin. This indolamine acts as both antioxidant and scavenger not just extracellularly but also intracellularly, including the nucleus (Reiter et al. 2007, 2010). Moreover, melatonin increases the bioavailability of nitric oxide with its antiproliferative effect (Paulis et al. 2009, Rezzani et al. 2010, Simko et al. 2010) and interferes with several neurohumoral systems including sympathetic and renin-angiotensin systems (Simko et al. 2013).

We conclude that in continuous light-induced hypertension, administration of melatonin, along with blood pressure reduction, decreases collagen I and III concentration in the media of aorta. This action of melatonin could improve the elasticity of aorta and other conduit arteries. We speculate that the antifibrotic effect of melatonin in the aorta and potentially in smaller arteries may beneficially influence the nature of the pulse wave and peripheral vascular resistance and could mitigate the undesirable alterations of the vascular system in conditions of hypertension, aging or chronic neurohumoral activation.

\section{Conflict of Interest}

There is no conflict of interest.

\section{Acknowledgements}

This study was supported by grants for scientific research of VEGA No 1/0227/12, 1/0831/11 and 2/0183/12, of APVV-0205-12 and by the programme PRVOUK P37/5.

\section{References}

ARANGINO S, CAGNACCI A, ANGIOLUCCI M, VACCA AM, LONGU G, VOLPE A, MELIS GB: Effects of melatonin on vascular reactivity, catecholamine levels, and blood pressure in healthy men. Am J Cardiol 83: 1417-1419, 1999.

DOBRIN PB, MRKVICKA R: Failure of elastin or collagen as possible critical connective tissue alterations underlying aneurysmal dilatation. Cardiovasc Surg 2: 484-488, 1994.

DOMINGUEZ-RODRIGUEZ A, ABREU-GONZALEZ P, SANCHEZ-SANCHEZ JJ, KASKI JC, REITER RJ: Melatonin and circadian biology in human cardiovascular disease. J Pineal Res 49: 14-22, 2010.

GROSSMAN E, LAUDON M, YALCIN R, ZENGIL H, PELEG E, SHARABI Y, KAMARI Y, SHEN-ORR Z, ZISAPEL N: Melatonin reduces night blood pressure in patients with nocturnal hypertension. Am J Med 119: 898-902, 2006.

GROSSMAN E, LAUDON M, ZISAPEL N: Effect of melatonin on nocturnal blood pressure: meta-analysis of randomized controlled trials. Vasc Health Risk Manag 7: 577-584, 2011.

IVANISEVIC-MILOVANOVIC OK, DEMAJO M, KARAKASEVIC A, PANTIC V: The effect of constant light on the concentration of catecholamines of the hypothalamus and adrenal glands, circulatory hadrenocorticotropin hormone and progesterone. J Endocrinol Invest 18: 378-383, 1995.

JONAS M, GARFINKEL D, ZISAPEL N, LAUDON M, GROSSMAN E: Impaired nocturnal melatonin secretion in non-dipper hypertensive patients. Blood Press 12: 19-24, 2003. 
LI HL, KANG YM, YU L, XU HY, ZHAO H: Melatonin reduces blood pressure in rats with stress-induced hypertension via GABAA receptors. Clin Exp Pharmacol Physiol 36: 436-440, 2009.

MILOSEVIC V, TRIFUNOVIC S, SEKULIC M, SOSIC-JURJEVIC B, FILIPOVIC B, NEGIC N, NESTOROVIC N, MANOJLOVIC STOJANOSKI M, STARCEVIC V: Chronic exposure to constant light affects morphology and secretion of adrenal zona fasciculata cells in female rats. Gen Physiol Biophys 24: 299-309, 2005.

PAULIS L, SIMKO F: Blood pressure modulation and cardiovascular protection by melatonin: potential mechanisms behind. Physiol Res 56: 671-684, 2007.

PAULIS L, PECHANOVA O, ZICHA J, KRAJCIROVICOVA K, BARTA A, PELOUCH V, ADAMCOVA M, SIMKO F: Melatonin prevents fibrosis but not hypertrophy development in the left ventricle of NG-nitro-Larginine-methyl ester hypertensive rats. J Hypertens Suppl 27: S11-S16, 2009.

PAULIS L, PECHANOVA O, ZICHA J, BARTA A, GARDLIK R, CELEC P, KUNES J, SIMKO F: Melatonin interactions with blood pressure and vascular function during L-NAME-induced hypertension. J Pineal Res $\mathbf{4 8 :}$ 102-108, 2010a.

PAULIS L, PECHANOVA O, ZICHA J, LISKOVA S, CELEC P, MULLEROVA M, KOLLAR J, BEHULIAK M, KUNES J, ADAMCOVA M, SIMKO F: Melatonin improves the restoration of endothelium-derived constricting factor signalling and inner diameter in the rat femoral artery after cessation of L-NAME treatment. J Hypertens 28 (Suppl 1): S19-S24, 2010b.

PAULIS L, SIMKO F, LAUDON M: Cardiovascular effects of melatonin receptor agonists. Expert Opin Investig Drugs 21: 1661-1678, 2012.

PECHANOVA O, ZICHA J, PAULIS L, ZENEBE W, DOBESOVA Z, KOJSOVA S, JENDEKOVA L, SLADKOVA M, DOVINOVA I, SIMKO F, KUNES J: The effect of N-acetylcysteine and melatonin in adult spontaneously hypertensive rats with established hypertension. Eur J Pharmacol 561: 129-136, 2007.

PELOUCH V, MILEROVA M, OSTADAL B, HUCIN B, SAMANEK M: Differences between atrial and ventricular protein profiling in children with congenital heart disease. Mol Cell Biochem 147: 43-49, 1995.

RECHCINSKI T, TRZOS E, WIERZBOWSKA-DRABIK K, KRZEMINSKA-PAKULA M, KURPESA M: Melatonin for nondippers with coronary artery disease: assessment of blood pressure profile and heart rate variability. Hypertens Res 33: 56-61, 2010.

REITER RJ, TAN DX, TERRON MP, FLORES LJ, CZARNOCKI Z: Melatonin and its metabolites: new findings regarding their production and their radical scavenging actions. Acta Biochim Pol 54: 1-9, 2007.

REITER RJ, TAN DX, FUENTES-BROTO L: Melatonin: a multitasking molecule. Prog Brain Res 181: 127-151, 2010.

REZZANI R, PORTERI E, DE CIUCEIS C, BONOMINI F, RODELLA LF, PAIARDI S, BOARI GE, PLATTO C, PILU A, AVANZI D, RIZZONI D, AGABITI ROSEI E: Effects of melatonin and Pycnogenol on small artery structure and function in spontaneously hypertensive rats. Hypertension 55: 1373-1380, 2010.

SCHEER FA, VAN MONTFRANS GA, VAN SOMEREN EJ, MAIRUHU G, BUIJS RM: Daily nighttime melatonin reduces blood pressure in male patients with essential hypertension. Hypertension 43: 192-197, 2004.

SCHIFFRIN EL: Vascular remodeling in hypertension: mechanisms and treatment. Hypertension 59: 367-374, 2012.

SIMKO F, PAULIS L: Melatonin as a potential antihypertensive treatment. J Pineal Res 42: 319-322, 2007.

SIMKO F, PAULIS L. Hypertensive heart disease: bone marrow as a significant player in pathologic remodelling? J Hypertens 30: 1702-1705, 2012.

SIMKO F, PAULIS L: Antifibrotic effect of melatonin - perspective protection in hypertensive heart disease. Int $J$ Cardiol 168: 2876-2877, 2013.

SIMKO F, PECHANOVA O: Potential roles of melatonin and chronotherapy among the new trends in hypertension treatment. J Pineal Res 47: 127-133, 2009.

SIMKO F, SIMKO J, FABRYOVA M: ACE-inhibition and angiotensin II receptor blockers in chronic heart failure: pathophysiological consideration of the unresolved battle. Cardiovasc Drugs Ther 17: 287-290, 2003.

SIMKO F, MATUSKOVA J, LUPTAK I, KRAJCIROVICOVA K, KUCHARSKA J, GVOZDJAKOVA A, BABAL P, PECHANOVA O: Effect of simvastatin on remodeling of the left ventricle and aorta in L-NAME-induced hypertension. Life Sci 74: 1211-1224, 2004. 
SIMKO F, PECHANOVA O, PELOUCH V, KRAJCIROVICOVA K, MULLEROVA M, BEDNAROVA K, ADAMCOVA M, PAULIS L: Effect of melatonin, captopril, spironolactone and simvastatin on blood pressure and left ventricular remodelling in spontaneously hypertensive rats. J Hypertens Suppl 27: S5-S10, 2009.

SIMKO F, PECHANOVA O, PELOUCH V, KRAJCIROVICOVA K, CELEC P, PALFFY R, BEDNAROVA K, VRANKOVA S, ADAMCOVA M, PAULIS L: Continuous light and L-NAME-induced left ventricular remodelling: different protection with melatonin and captopril. J Hypertens 28 (Suppl 1): S13-S18, 2010.

SIMKO F, REITER RJ, PECHANOVA O, PAULIS L: Experimental models of melatonin-deficient hypertension. Front Biosci-Landmark 18: 616-625, 2013.

TENGATTINI S, REITER RJ, TAN DX, TERRON MP, RODELLA LF, REZZANI R: Cardiovascular diseases: protective effects of melatonin. J Pineal Res 44: 16-25, 2008.

WEBER KT: Cardiac interstitium in health and disease: the fibrillar collagen network. J Am Coll Cardiol 13: $1637-$ $1652,1989$.

XIA CM, SHAO CH, XIN L, WANG YR, DING CN, WANG J, SHEN LL, LI L, CAO YX, ZHU DN: Effects of melatonin on blood pressure in stress-induced hypertension in rats. Clin Exp Pharmacol Physiol 35: 1258$1264,2008$.

ZEMAN M, DULKOVA K, BADA V, HERICHOVA I: Plasma melatonin concentrations in hypertensive patients with the dipping and non-dipping blood pressure profile. Life Sci 76: 1795-1803, 2005. 